\title{
Post-traumatic diabetes insipidus combined with primary polydipsia
}

\author{
M. Labib, G. McPhate and V. Marks \\ Department of Clinical Biochemistry, St Luke's Hospital, Guildford, Surrey GU1 3NT, UK.
}

\begin{abstract}
Summary: We describe a case of diabetes insipidus after head injury in which thirst persisted despite treatment with DDAVP and normal plasma osmolality. Symptoms were only completely relieved when plasma osmolality was below $270 \mathrm{mosmol} / \mathrm{kg}$. We believe that this might have been due to hypothalamic injury causing resetting of the thirst osmostat. To our knowledge, this type of primary polydipsia has not been described before in association with diabetes insipidus following head injury.
\end{abstract}

\section{Introduction}

Primary polydipsia may occur in patients with severe mental or emotional disturbances. ${ }^{1}$ It may also occur in patients with organic hypothalamic pituitary disease ${ }^{2}$ or in association with cerebral damage. It has not been described in association with diabetes insipidus due to head injury.

We report a patient who developed diabetes insipidus after head injury, whose symptoms were only completely relieved when his plasma osmolality was reduced below $270 \mathrm{mosmol} / \mathrm{kg}$. We interpret this case as one of combined diabetes insipidus and primary polydipsia due to post-traumatic hypothalamic injury.

\section{Case report}

A 20 year old man was admitted following a motorcycle accident in which he fractured his left frontal, parietal and temporal bones. He had bilateral periorbital haematomas with proptosis for which he underwent bilateral decompression. After 4 weeks he developed polydipsia and polyuria. Drinking reduced his thirst for only a few minutes and diabetes insipidus was suspected. His 24 hour urine volume was $9100 \mathrm{ml}$ with a urine osmolality of $60 \mathrm{mosmol} / \mathrm{kg}$ and his plasma osmolality was $277 \mathrm{mosmol} / \mathrm{kg}$. The osmolality was measured by freezing point depression using a HALBMIKRO osmometer (Knauer \& Co., West

Correspondence: M.H. Labib, M.B., Ch.B., M.R.C. Path. Accepted: 30 July 1986
Germany). The reference range for normal healthy individuals under basal conditions in our laboratory is $280-295 \mathrm{mosmol} / \mathrm{kg}$. The coefficient of variation is $0.83 \%$ at $286 \mathrm{mosmol} / \mathrm{kg}$ and $0.78 \%$ at $325 \mathrm{mosmol} / \mathrm{kg}$.

An 8 hour water deprivation test showed a maximum plasma osmolality of $298 \mathrm{mosmol} / \mathrm{kg}$ with a simultaneous urine osmolality of $317 \mathrm{mosmol} / \mathrm{kg}$ which increased to $590 \mathrm{mosmol} / \mathrm{kg}$ after $2 \mu \mathrm{g}$ desmopressin (DDAVP) intramuscularly. In normal individuals, urine osmolality after 8 hours' water deprivation exceeds $750 \mathrm{mosmol} / \mathrm{kg}$ and does not increase after DDAVP. In patients with cranial diabetes insipidus the urine osmolality is usually lower than plasma osmolality after dehydration but increases to $>750 \mathrm{mosmol} / \mathrm{kg}$ after DDAVP. In our patient urine osmolality was higher than plasma osmolality after dehydration and showed a further increase after DDAVP but only to $590 \mathrm{mosmol} / \mathrm{kg}$. These results were interpreted as being due to partial diabetes insipidus together with a degree of polyuriainduced nephrogenic diabetes insipidus. The patient was put on a therapeutic trial of $2 \mu \mathrm{g}$ DDAVP intramuscularly daily. Twelve hours after commencing DDAVP plasma osmolality decreased to 283 mos$\mathrm{mol} / \mathrm{kg}$ but he remained extremely thirsty. Consequently, fluid intake was restricted to the previous 24 hour output in an attempt to maintain plasma osmolality above $280 \mathrm{mosmol} / \mathrm{kg}$. For the following 10 days urine volumes ranged between 3.0 and 4.5 litres/day and despite plasma osmolalities between 280 and 285 mosmol/kg he remained extremely thirsty. He was

(C) The Fellowship of Postgraduate Medicine, 1987 
Table I Prolonged water deprivation test (19 hours)

\begin{tabular}{|c|c|c|c|c|c|}
\hline & $\begin{array}{c}\text { Plasma } \\
\text { osmolality } \\
\text { (mosmol/kg) }\end{array}$ & $\begin{array}{c}\text { Urine } \\
\text { osmolality } \\
\text { (mosmol/kg) }\end{array}$ & $\begin{array}{l}\text { Cumulative } \\
\text { volume ( } \mathrm{ml})\end{array}$ & $\begin{array}{c}\text { Plasma } \\
\text { AVP } \\
\text { (pmol/l) }\end{array}$ & $\begin{array}{c}\text { Weight } \\
\text { (kg) }\end{array}$ \\
\hline $\begin{array}{l}\text { Pre-water deprivation } \\
\text { Post-water deprivation }\end{array}$ & \multicolumn{5}{|c|}{ Post-water deprivation } \\
\hline 9 hours & 292 & 95 & 2700 & 0.12 & \\
\hline 11 hours & 295 & 95 & 3370 & & \\
\hline 13 hours & 305 & 230 & 3492 & & \\
\hline 15 hours & 305 & 185 & 3767 & & \\
\hline 17 hours & 302 & 295 & 3872 & 0.08 & \\
\hline 19 hours & 300 & 338 & 3977 & & 52 \\
\hline \multicolumn{6}{|l|}{ After $2 \mu \mathrm{g}$ DDAVP i.m. } \\
\hline 12 hours & 283 & 730 & & & \\
\hline
\end{tabular}

then allowed free access to water for 2 days and plasma osmolality dropped to 262 on the first day and $265 \mathrm{mosmol} / \mathrm{kg}$ on the second. Compulsive water drinking was suspected. Because of the atypical response to DDAVP, the drug was stopped and a prolonged water deprivation test was performed (see Table I). The starting plasma osmolality was 270 mosmol $/ \mathrm{kg}$. Nineteen hours of water deprivation produced plasma hyperosmolality (305 mosmol $/ \mathrm{kg}$ ) and a $7 \%$ weight loss. Maximum urine osmolality was $338 \mathrm{mosmol} / \mathrm{kg}$ rising to $730 \mathrm{mosmol} / \mathrm{kg}$ after $2 \mu \mathrm{g}$ DDAVP i.m. Plasma arginine vasopressin (AVP) was determined, at the SAS Laboratory, Middlesex Hospital, by radioimmunoassay, ${ }^{3}$ and was low for the corresponding plasma osmolality (Table I). The results confirmed diabetes insipidus, but this diagnosis did not explain the low starting plasma osmolality $(270 \mathrm{mosmol} / \mathrm{kg})$. Treatment with DDAVP $2 \mu \mathrm{g}$ i.m. daily was recommenced and the patient allowed free access to water. After 24 hours plasma osmolality had dropped to $269 \mathrm{mosmol} / \mathrm{kg}$ and the patient reported satisfactory relief of his thirst. For the following 4 weeks, plasma osmolality remained between 263 and $270 \mathrm{mosmol} / \mathrm{kg}$ (i.e. hyposmolar), mean daily urine output was 2 litres and he no longer complained of thirst.

\section{Discussion}

Diabetes insipidus is a well recognized sequel of head injury. It presents with polydipsia and polyuria and a plasma osmolality which is usually slightly increased. This contrasts with the low plasma osmolality of primary polydipsia. In our patient, despite confirmation of diabetes insipidus plasma osmolality was low.

Antidiuretic therapy, rarely, if ever, leads to significant hyposmolality in patients with diabetes insipidus because their thirst mechanism is intact. On the other hand, in patients with compulsive water drink- ing, antidiuretic therapy may cause severe hyposmolality because they do not reduce their water intake. Our patient reacted atypically to the antidiuretic therapy in that he was still extremely thirsty when his plasma osmolality was normal. Thirst was completely relieved only when plasma osmolality fell below $270 \mathrm{mosmol} / \mathrm{kg}$. In contrast to patients with psychogenic polydipsia, plasma osmolality never fell below $263 \mathrm{mosmol} / \mathrm{kg}$ at which level his thirst was quenched. Thirst is normally absent when plasma osmolality is below $290 \mathrm{mosmol} / \mathrm{kg}$. Therefore, wo interpret the disturbance in this patient as being due to abnormal resetting of his thirst osmostat rather that to compulsive water drinking. His thirst sensation di đa respond to plasma osmolality but at a lower level than normal. We believe that he has a variety of primary polydipsia which has recently been called the syndrome of inappropriate thirst'. ${ }^{4}$

The osmoreceptors that control thirst have many properties in common with those regulating the secretion of AVP. Anatomically, the thirst osmoreceptors appear to be located in similar, if not identical areas in the hypothalamus. Clinical and experimental data show that destructive lesions in the hypothalamus can abolish osmoregulation of thirst and/or AVP secretion. $^{5}$ It is surprising that despite the well-known association between head injury and diabetes insipidus, no case of diabetes insipidus combined with primary polydipsia to our knowledge, has been so far reported after head injury.

\section{Acknowledgements}

The patient was under the care of Dr J.P. Patten, Consultant Neurologist, whom we thank for helpful discussions concerning the management of this patient. We would also like to thank Dr M.L. Forsling for performing the AVP assays.

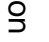
. (2) $\overrightarrow{0}$ , 


\section{References}

1. Barlow, E.D. \& De Wardener, H.E. Compulsive water drinking. $Q J$ Med 1959, 28: 235-258.

2. Stuart, C.A., Neelson, F.A. \& Lebovitz, H.E. Disordered control of thirst in hypothalamic pituitary sarcoidosis. $N$ Engl J Med 1980, 303: 1078-1082.

3. Forsling, M.L. \& Williams, H. Central effects of dopamine on vasopressin release in the normally hydrated and water-loaded rat. $J$ Physiol 1984, 346: 49-59.
4. Mellinger, R.C. \& Zafar, M.S. Primary polydipsia, syndrome of inappropriate thirst. Arch Intern Med 1983, 143: 1249-1251.

5. Robertson, G.L., Athar, S. \& Shelton, R.L. Osmotic control of vasopressin function. In Audreoli, T.E., Grantham, J.J. \& Reetor, F.C. Jr (eds) Disturbances in Body Fluid Osmolality, American Physiological Society, Bethesda, 1977, 125-148. 